\title{
Effectiveness of Home-Based Cardiac Rehabilitation and Its Importance During COVID-19
}

\author{
Hannah Pollock $^{1}$ | Anna Garnett ${ }^{1}$
}

${ }^{1}$ Arthur Labatt Family School of Nursing, Western University, London, ON, Canada

\section{Correspondence}

Hannah Pollock

Email: hpolloc2@uwo.ca

Publication Date

June 25, 2021

\section{MJM 2022 (20) 2}

https://doi.org/10.26443/mjm.v20i1.857

\section{के McGill Journal of Medicine}

www.mjmmed.com

\section{cc) (†)(2)}

This work is licensed under a Creative Commons BY-NC-SA 4.0 International License.

\begin{abstract}
A B STRACT
Cardiac rehabilitation is a secondary prevention and diseasemanagement opportunity for individuals living with cardiovascular disease. The COVID-19 pandemic has caused postponements and cancellations for many health services, including $41 \%$ of cardiac rehabilitation programs in Canada. Cardiac rehabilitation effectively reduces the risk of mortality, morbidity, and hospitalizations in cardiac clients. Without access, individuals face challenges to improve their health, which places them at risk of adverse outcomes. This paper argues that transitioning to home-based cardiac rehabilitation programs during the pandemic is a reasonable strategy to meet the ongoing rehabilitation needs of cardiac patients. Home-based cardiac rehabilitation programs utilize limited hospital or clinic visits because the majority of exercise is performed at home through regular communication with a case manager. Programs utilize a variety of resources, including technology, to regularly monitor, educate, and counsel clients. The programs' flexibility and convenience overcome many multi-level barriers which normally impede participants from accessing services. These programs have proven to be equally effective, if not more effective than centre-based programs, at improving mortality, cardiac events, exercise capacity and modifiable risk factors. Homebased programs are a valid alternative to support and protect a vulnerable population, especially those at high risk if diagnosed with COVID-19. Transitioning to a home-based platform may be a challenge, but the Canadian Cardiovascular Society has provided practical approaches to support programs. Adapting current plans and developing new ones, utilizing appropriate resources, having a conservative exercise program, monitoring clients, emphasizing education, being flexible, and enhancing safety are key steps for a successful transition.
\end{abstract}

\section{KEYWORDS}

Cardiac Rehabilitation, COVID-19, Home-Based, Tele-Rehabilitation, Virtual Health 


\section{1 | INTRODUCTION}

The novel coronavirus disease (COVID-19) was declared a global pandemic in March 2020 and has caused disturbances in every aspect of life, particularly for vulnerable groups such as those living with chronic disease. $(1,2,3)$ The pandemic has caused many disturbances in healthcare by cancelling or postponing services to prevent the spread of COVID-19 and prepare for a potential surge in patients that could deplete resources. (4) This included the closure of approximately $41 \%$ of cardiac rehabilitation (CR) programs across Canada. (5) These closures can potentially cause adverse short- and long-term consequences for attendees, such as increased rates of cardiac events, emergency room visits, hospital admissions, and potential exposure to COVID-19, consequently further depleting healthcare resources. $(6,7) \mathrm{CR}$ is defined as "the enhancement and maintenance of cardiovascular health through individualized programs designed to optimize physical, psychological, social, vocational, and emotional status." (8) CR is a secondary prevention and disease-management opportunity for those who have experienced an acute cardiac event, those with chronic cardiovascular disease, those who have undergone cardiovascular procedures, and those with cardiovascular risk factors. $(9,10)$ Through health education and selfmanagement opportunities, CR aims to reverse or prevent disease progression and reduce the recurrence of cardiac events, helping participants improve and take control of their health and wellbeing. (8)

COVID-19 has made it more challenging for this group to engage with resources such as CR due to closures. Alternative ways to deliver care are recommended and have been implemented for many healthcare services, and CR should be no different. (4) In Ontario, only about $10 \%$ of CR participants undergo homebased CR, often due to clinical factors such as those at high risk of complications or those with a low functional status requiring more supervision. (11) Home-based CR is a highly underutilized resource shown to be just as effective as centre-based programs when implemented appropriately. (12-19) Through advocacy and innovation, healthcare providers and health leaders can utilize new and existing strategies to meet the current challenge of delivering this important component of rehabilitation. Doing so will enable people to achieve optimal health gains by properly managing their cardiovascular disease. The following paper suggests that given the current COVID-19-related constraints on in-person health services, transitioning to a home-based CR program is a reasonable strategy that will enable clinicians and administrators to meet the ongoing rehabilitation needs of cardiac clients.

\section{I CARDIAC REHABILITATION IN CANADA PRE-PANDEMIC}

Cardiovascular disease is the second leading cause of death in Canada and the leading cause of death globally, with 8.9 million deaths worldwide in 2015. (20) Between 2012 and 2013, about 2.4 million Canadians were living with cardiovascular disease. (20) All-cause mortality rates for cardiovascular disease have declined over the years, reflecting improvements in treatment, disease management, rehabilitation, and public health interventions. (20) As more people survive acute cardiac events and continue to live with cardiovascular disease, they may also experience negative impacts on their quality of life for a longer period of time. (20) Programs such as CR are essential to optimize recovery and limit mortality.

$\mathrm{CR}$ programs have been proven to reduce the risk of cardiovascular mortality, morbidity, and hospitalization through the use of a therapeutic process involving five core components: (i) risk factor assessment and management, (ii) structured exercise training, (iii) nutrition counselling, (iv) patient education, and (v) psychosocial counselling. $(8,21-25)$ In Ontario, a retrospective matched cohort study found that $\mathrm{CR}$ reduces mortality by $50 \%$ when comparing $C R$ versus non CR participants in a sample of matched hospitalized cardiac clients. (25) Over 200 CR programs in Canada are delivered primarily in a supervised center-based facility by an interprofessional team of healthcare providers. $(11,26)$ Typically, programs offer two multi-dimensional sessions per 
week that consist of exercise, education, assessment, and counselling that are delivered over a period of five months. (11)

Although the benefits of CR have been shown, this resource is still widely unavailable and underused, with only $75-80 \%$ of eligible individuals participating, due to multi-level barriers such as low referral rates, geographic location, financial constraints, inequitable access, and more. (7, 11, 24, 27-31) In Canada, there is only one CR spot per 4.55 people who require it, and 186,187 more spots are needed annually to meet current demands. (32) Ontario would need about 35,183 more CR spots to treat those identified through hospitalization alone. (11) The literature shows that CR availability and accessibility is an issue, and the new COVID19 pandemic has added considerable complications for those delivering programs and individuals requiring the service.

\section{I IMPACT OF COVID-19 ON CARDIAC REHABILITATION PRO- GRAMS}

Approximately $41 \%$ of CR programs in Canada completely closed at some point during the COVID-19 pandemic. (5) In-person services were cancelled or postponed due to recommendations by governments and public health agencies to limit the spread of the virus. $(6,7,33)$ Closures were mainly a result of staff redeployment, facilities being located in a hospital or highrisk facility, repurposing the facility for use in the effort against COVID-19, lack of funding, and lack of leadership. (5) CR programs that had established virtual homebased programs pre-pandemic as an alternative or supplement to their centre-based program were able to implement that full time. $(5,7)$ In contrast, others had to create and transition from their regular programs to an entirely home-based program. (5) As such, fewer services were offered, with many being delivered through the telephone, email, postal mail, or web-based platforms, posing new challenges for clients and healthcare providers. $(5,7)$
With lockdowns and physical distancing measures in place, individuals living with cardiovascular disease are at a greater risk of increasing their sedentary choices, decreasing physical activity, making poor nutrition choices, and suffering from mental health issues, thus increasing their risk of acute cardiovascular events and long-term consequences. $(7,33)$ In the absence of CR programs, individuals are unable to engage in valuable health education on cardiovascular risk, health nutrition, cognitive and behavioural symptom management, and safe exercise habits with the guidance and support of a healthcare provider.

In addition, the impact of COVID-19 is more severe in older adults living with comorbidities. $(2,3)$ Casefatality rate is $8.0 \%$ in those aged 70 to $79,14.8 \%$ in those aged 80 and older, and $10.5 \%$ specifically in those with cardiovascular disease. (2) With the majority of individuals living with cardiovascular disease being 65 years and older, they are at high risk if diagnosed with COVID-19. Maintaining resources, such as CR, that promote and protect their health is critical during this time. $(2,34)$

Although programs have rightly sought to limit the spread of COVID-19 and protect a vulnerable population, the short- and long-term consequences of these actions may result in collateral declines in health that could have serious implications for the individuals and the health system. Alternatives such as home-based programs can be instated to offset these potential consequences.

\section{4 | HOME-BASED CARDIAC REHA- BILITATION PROGRAMS}

\section{1 | Structure}

The Canadian Cardiac Rehabilitation Association explains that home-based CR programs utilize limited hospital or clinic visits, typically for low to moderate risk cardiac clients. (8) The majority of exercise training is performed at home through regular communication with a case manager for follow-up, education, and counselling. $(8,24,35-37)$ Some programs may use advanced tech- 
nology with clients wearing sensors for real-time monitoring of physiological signs by healthcare providers. (38) Regardless of the program structure, frequent and regular monitoring is always integral to all programs whether this monitoring be through in-person meetings, mail, telephone, email, or online chat sessions. (17, 24, $30,33,39)$ Independence is a key component, relying on the client's ability and motivation to self-manage. These programs have been introduced as a potential strategy to overcome some of the multi-level barriers experienced by individuals and programs when trying to offer and engage in traditional centre-based CR.

\section{2 | Answer to Multi-Level Barriers}

Multi-level barriers to CR occur at the individual, program, community, and health system levels. Individuals face issues like geographic location, transportation, financial factors (costs associated with attending in person such as parking and transit), and inclement weather. (11, 24, 27-31) Individuals may also suffer from comorbidities or compromised functional abilities, making it challenging to attend appointments in-person. (24, 29, 30) Furthermore, home and professional responsibilities may further constrain clients' ability to attend appointments. (24, 27, 30) Additionally, individuals from marginalized groups such as those with low socioeconomic status, minority, and vulnerable groups have a disproportionately more difficult time accessing CR. (11, $27,30)$

At the program level, facilities can be constrained by space, personnel, or financial limitations, and they may be unable to offer the appropriate calibre of program required to meet the needs of the community. $(11,30)$ At the community level, a common barrier includes primary care providers who are unaware of available CR programs and its associated benefits. $(11,29)$ This results in a lack of referrals, a primary reason why those who qualify for CR do not attend. For example, policy guidelines from the Canadian Association of Cardiac Rehabilitation and the Canadian Cardiovascular Society recommend that at least $85 \%$ of individuals who require CR should be referred for CR and at least $70 \%$ should be enrolled. However, only $52 \%$ of clients in Ontario are referred for CR. $(11,40)$ At the health system level, a lack of reimbursement by the government limits programs' ability to properly serve their community. (11) The inability to adequately fund CR programs across the country impacts the accessibility and uptake of CR programs. (11)

\section{3 | Effectiveness of Home-Based Cardiac Rehabilitation}

Research suggests that home-based CR programs are equally effective, if not more effective than centrebased CR programs at improving the health and risk factors associated with cardiovascular disease. (12, 14-19, 41) In particular, home-based $C R$ programs have been shown to produce the same or improved rates of mortality and enhance the short and long-term exercise capacity of those who participate. $(12,13,16,18,19$, 28) These programs provide all of the core components of CR while being highly flexible and widely accessible. This accessibility helps overcome many of the barrier's individuals face when accessing centre-based CR programs. $(12,16,17,42)$

A Cochrane Database Systematic Review conducted by Anderson et al. (16) identified no difference between home-based and centre-based groups regarding mortality, cardiac events, exercise capacity, modifiable risk factors such as cholesterol, blood pressure, smoking, and health-related quality of life. However, it showed higher program completion levels and adherence for those in a home-based program. (16) Another recent systematic review by Jin et al. (19) looked specifically at the impact of telehealth interventions in home-based CR programs as an alternative or adjunct to usual care (any routine care for cardiovascular disease) or centre-based CR. The authors discovered no significant difference in mortality between telehealth interventions and usual care or centre-based CR. (19) However, the interventions did show significant beneficial results in the medium and long-term duration for the secondary prevention of cardiovascular disease compared to usual care and equivalent results compared to centre-based CR. (19) When 
used in combination with usual care or centre-based CR, even better results were evident. (19)

Adherence is one of the most critical aspects that determines an individuals' success in the program. Homebased CR participants often have superior adherence and completion rates than individuals receiving usual care or center-based care. $(12,14,28,41)$ This high level of adherence is due to its ability to address many barriers and its flexibility. $(42,43)$ Individuals have also expressed overall satisfaction with these programs. (31, 36-39, 41-43) These types of programs foster confidence, independence, and behaviour change and develop self-management skills that carry on postprogram. These skills enable individuals to better their health long-term. (30, 36-38, 41-43)

Overall, research has demonstrated that home-based CR programs are effective for risk reduction and positive behavioural outcomes in clients. Such programs are a useful adjunct or alternative to centre-based CR if appropriately used.

\section{4 | Challenges of Home-Based Cardiac Rehabilitation}

No healthcare intervention is perfect and home-based $\mathrm{CR}$ is no exception. Associated challenges include technology issues, lack of peer support, lack of motivation, lack of supervision, and privacy issues. (7, 33, 37-39, $42,43)$ A variety of technology issues can determine a participant's access and ability to successfully engage in home-based CR programs. For example, limitations pertaining to digital access can make it challenging to access virtual resources, inhibiting participant's ability to learn. $(7,37,38,42,43)$ In addition, a lack of digital literacy can hinder participants' ability to fully utilize virtual resources. $(37,39,42,43)$ Appropriate training is required for health providers and clients engaging with virtual platforms. (5) Furthermore, use of digital technology raises concerns around privacy and security. (33, 43) Client confidentiality is necessary in all situations and the use of technology adds a layer of complexity and risk that may deter participants from engaging in such programs.
In a centre-based program, participants are surrounded by peers and healthcare providers who make the program engaging and enjoyable which in turn promotes motivation. At home however, building the motivation to promote positive results can be difficult. (39) The lack of interpersonal support can significantly impede a participant's ability to maintain motivation. As well, concerns exist of increased risk for harm without professional oversight to ensure exercises are being performed properly. (39)

\section{5 | HOME-BASED CARDIAC RE- HABILITATION IN A COVID-19 WORLD}

With many other health services finding alternative ways to provide care, home-based $C R$ is a valid option to support clients. Transitioning to home-based programs will be challenging for provider organizations due to larger service requirements and increased need for resources, particularly related to digital platforms. (6)

The lack of standardized guidelines for delivery of home-based CR prior to the pandemic further complicates the process of shifting to a solely home-based format. The Canadian Cardiovascular Society (CCS) has provided some guidance on implementing virtual at home CR and included some practical approaches to support programs in their transition. (6) The overall goal is to prioritize basic, safe, and timely care until a program is established; afterwards, care should be shifted towards ensuring traditional standards are met. (6) Having an evaluation plan and adapting current plans as needed enhances sustainability. This is crucial in addressing program administration issues during the pandemic as well as gaps present prior to the pandemic. (7)

\section{1 | Practical Approaches to Implementation}

The CCS recommends that programs support staff in their transition towards virtual care. (6) Programs should utilize one suitable online resource for clients and staff 
to access information in order to avoid being overwhelmed by the number of resources available. (6) Upon initial interaction with clients, it is important to have intake assessments that discusses the potential risks and benefits with the understanding that minimal CR support is better than none. $(6,7)$

Though home-based CR programs are not suitable for everyone, programs should consider all clients eligible for home-based CR in some capacity, including exercise training. (6) Though risk-stratification can be a challenge, the emphasis should be on clinical assessment and alternative ways to assess risks, such as the selfadministered 6-Minute Walk Test and use of personal blood pressure machines. (6)

The CCS recommends that programs focus on CR core components, including lifestyle risk management, psychosocial supports, medical advice, education, and simple exercise prescriptions. (6) Home-based exercise programs should be conservative and slowly titrated to ensure safety. (6) Exercise programs should aim to provide the minimal level of physical activity to achieve health benefits without exceeding a moderate level of exercise intensity. (6) The use of self-assessment tools such as heart rate palpation, wearable heart rate monitors, and the 'talk test' can help determine the level of exercise intensity. (6) An increased emphasis should be placed on the signs and symptoms to monitor while exercising and the use of different technologies where available. (6)

The CCS also suggests that programs use digital platforms that enhance and facilitate program delivery, including group tele-/videoconferencing sessions, in order for education and support to reach more individuals. (6) Technology should be made available to clients in order to maximize uptake of remotely offered CR. (6) However, programs should initially plan to use and repurpose the resources they have over complex restructuring; this may include mailing paper-based education materials as required. $(6,7)$ Focusing on the resources available will allow for more rapid implementation of home-based programs and limit the loss of service provision to clients.

A recent study looking at the impact of COVID-19 on CR programs in Canada found that 35 of the 52 programs still running reported at least one web-based resource. (5) Technology use increased for education and the delivery of exercise programs. (5) These notions show that many programs have risen to the challenge of promoting continuity of care during the pandemic.

\section{6 | CONCLUSION}

While the COVID-19 pandemic continues without a clear end, continuing to optimize health and recovery is important for individuals living with cardiovascular disease. With the closure of many CR programs, cardiovascular clients are left vulnerable because they cannot access resources that support their health. Without this support, they are at an increased risk of acute cardiovascular events. Home-based CR provides a solution to ensure individuals continue to receive appropriate care, especially during physically and mentally difficult times. Through advocacy and innovation, healthcare providers and health leaders can utilize new and existing strategies to meet the current challenge of delivering this important component of rehabilitation. Through careful collaboration and planning, CR programs can continue their essential work during the COVID-19 pandemic while also addressing many inequities present pre-pandemic, developing a solution for years to come.

\section{REFERENCES}

1. World Health Organization. WHO Director- Generals opening remarks at the media briefing on COVID-19 [Internet]. [Place unknown]: World Health Organization; 2020. [cited 2020 Dec 14]. Available from: https://www.who.int/directorgeneral/speeches/detail/who-director-general-s-openingremarks-at-the-media-briefing-on-covid-19-11-march-2020.

2. Wu Z, McGooan J. Characteristics of and Important Lessons From the Coronavirus Disease: Summary of a Report of 72314 Cases From the Chinese Center for Disease Control and Prevention. JAMA. 2020 [cited 2021 Feb 6];323(13):1239-42. Available from: doi:10.1001/jama.2020.2648.

3. Wang L, Wang Y, Ye D, Liu Q. Review of the 2019 novel coronavirus (SARS-CoV-2) based on current evidence. Int J Antimicrob Agents. 2020 [cited 2021 Feb 6];55(6):105948. Available from: https://doi.org/10.1016/j.ijantimicag.2020.105948. 
4. Canada. COVID-19 pandemic guidance for the health care sector. [Internet]. [Place unknown]: Government of Canada; 2020. [cited 2021 Feb 6]. Available from: https://www.canada.ca/en/public-health/services/diseases/2019novel-coronavirus-infection/health-professionals/covid-19-

pandemic-guidance-health-care-sector.html\#a3.

5. Marzolini S, Ghisi GM, Hébert A-A, Ahden S, Oh P. Cardiac Rehabilitation in Canada during COVID-19. CJC Open. 2020 [Internet]. [cited 2020 Dec 14]. Available from: doi: 10.1016/j.cjco.2020.09.021.

6. Canadian Cardiovascular Society. Guidance from the CCS COVID-19 rapid response team- the new "virtual reality": practical approaches to the delivery of cardiac rehabilitation care during the COVID-10 crisis [Internet]. [Place unknown]: Canadian Cardiovascular Society; 2020 [cited 2020 Dec 14]. Available from: https://ccs.ca/app/uploads/2020/12/Cardiac_Rehab_In_Covid_ v2.4_Final_17_May_313.pdf.

7. Moulson N, Bewick D, Selway T, Harris J, Suskin N, Oh P, et al. Cardiac Rehabilitation During the COVID-19 Era: Guidance on Implementing Virtual Care. Can J Cardiol [Internet]. 2020 [cited 2020 Dec 14];36(8):1317-21. Available from: doi: 10.1016/j.cjca.2020.06.006.

8. Canadian Association of Cardiac Rehabilitation. Canadian Guidelines for Cardiac Rehabilitation and Cardiovascular Disease Prevention. 3rd ed. Winnipeg: Canadian Association of Cardiac Rehabilitation; 2009 [cited 2020 Dec 14].

9. Cardiac Care Network. Standards for the Provision of Cardiovascular Rehabilitation in Ontario. Toronto: Cardiac Care Network; 2014 [cited 2020 Dec 14].

10. Heart and Stroke Foundation. Cardiac Rehabilitation (Cardiac Rehab) [Internet]. [Place unknown]. Heart and Stroke Foundation; 2020 [cited 2021 Feb 6]. Available from: https://www.heartandstroke.ca/heart-disease/recovery-andsupport/cardiac-rehabilitation.

11. Grace SL, Turk-Adawi K, Santiago de Araujo Pio C, Alter DA. Ensuring Cardiac Rehabilitation Access for the Majority of Those in Need: A Call to Action for Canada. Can J Cardiol [Internet]. 2016 [cited 2020 Dec 14];32(10 Suppl 2):S358-S64. Available from: doi: 10.1016/j.cjca.2016.07.001.

12. Dalal HM, Zawada A, Jolly K, Moxham T, Taylor RS. Home based versus centre based cardiac rehabilitation: Cochrane systematic review and meta-analysis. BMJ [Internet]. 2010 [cited 2020 Dec 14];340:b5631. Available from: doi:10.1136/bmj.b5631.

13. Ramadi A, Haennel RG, Stone JA, Arena R, Threlfall TG, Hitt $E$, et al. The sustainability of exercise capacity changes in home versus center-based cardiac rehabilitation. J Cardiopulm Rehabil Prev [Internet]. 2015 [cited 2020 Dec 14];35(1):21-8. Available from: doi:10.1097/HCR.0000000000000084.

14. Gabelhouse J, Eves N, Grace SL, Reid RC, Caperchione CM. Traditional versus hybrid outpatient cardiac rehabilitation: A comparison of patient outcomes. J Cardiopulm Rehabil Prev [Inter- net]. 2018 [cited 2020 Dec 14];38(4):231-8. Available from: doi:10.1097/HCR.0000000000000253.

15. Smith KM, McKelvie RS, Thorpe KE, Arthur HM. Six-year followup of a randomised controlled trial examining hospital versus homebased exercise training after coronary artery bypass graft surgery. Heart [Internet]. 2011 [cited 2020 Dec 14];97(14):1169-74. Available from: doi:10.1136/hrt.2010.202036.

16. Anderson L, Sharp GA, Norton RJ, Dalal H, Dean SG, Jolly $K$, et al. Home-based versus centre-based cardiac rehabilitation. Cochrane Database Syst Rev [Internet]. 2017 [cited 2020 Dec 14];6:CD007130. Available from: doi: 10.1002/14651858.CD007130.pub4.

17. Lear SA, Singer J, Banner-Lukaris D, Horvat D, Park JE, Bates $\mathrm{J}$, et al. Randomized trial of a virtual cardiac rehabilitation program delivered at a distance via the Internet. Circ Cardiovasc Qual Outcomes [Internet]. 2014 [cited 2020 Dec 14];7(6):952-9. Available from: doi:10.1161/CIRCOUTCOMES.114.001230.

18. Claes J, Buys R, Budts W, Smart N, Cornelissen VA. Longerterm effects of home-based exercise interventions on exercise capacity and physical activity in coronary artery disease patients: A systematic review and meta-analysis. Eur J Prev Cardiol [Internet]. 2017 [cited 2020 Dec 14];24(3):244-56. Available from: doi:10.1177/2047487316675823.

19. Jin K, Khonsari S, Gallagher R, Gallagher P, Clark AM, Freedman B, Briffa T, Bauman A, Redfer J, Neubeck L. Telehealth interventions for the secondary prevention of coronary heart disease: A systematic review and meta-analysis. EJCN [Internet]. 2019 [cited 2020 Dec 14];18(4):260-71. Available from: Doi: 10.1177/1474515119826510.

20. Canada. Report from the Canadian Chronic Disease Surveillance System: Heart Disease in Canada [Internet]. Ottawa: Public Health Agency of Canada; 2018. Available from: https://www.canada.ca/en/publichealth/services/publications/diseases-conditions/report-heartdisease-Canada-2018.html. [Accessed 3rd January 2021].

21. Kabboul NN, Tomlinson G, Francis TA, Grace SL, Chaves G, Rac V, et al. Comparative Effectiveness of the Core Components of Cardiac Rehabilitation on Mortality and Morbidity: A Systematic Review and Network Meta-Analysis. J Clin Med [Internet]. 2018 [cited 2020 Dec 14];7(12). Available from: doi:10.3390/jcm7120514.

22. Anderson L, Thompson DR, Oldridge N, Zwisler AD, Rees $\mathrm{K}$, Martin N, et al. Exercise-based cardiac rehabilitation for coronary heart disease. Cochrane Database Syst Rev [Internet]. 2016 [cited 2020 Dec 14];(1):CD001800. Available from: doi: 10.1002/14651858.CD001800.pub3.

23. Martin BJ, Hauer T, Arena R, Austford LD, Galbraith PD, Lewin $A M$, et al. Cardiac rehabilitation attendance and outcomes in coronary artery disease patients. Circulation [Internet]. 2012 [cited 2020 Dec 14];126(6):677-87. Available from: doi:10.1161/CIRCULATIONAHA.111.066738. 
24. Sandesara PB, Dhindsa D, Khambhati J, Lee SK, Varghese T, O'Neal WT, et al. Reconfiguring Cardiac Rehabilitation to Achieve Panvascular Prevention: New Care Models for a New World. Can J Cardiol [Internet]. 2018 [cited 2020 Dec 14];34(10):S231-S9. Available from: doi: 10.1016/j.cjca.2018.07.013.

25. Alter DA, Oh PI, Chong A. Relationship between cardiac rehabilitation and survival after acute cardiac hospitalization within a universal health care system. Eur J Cardiovasc Prev Rehabil [Internet]. 2009 [cited 2020 Dec 14];16(1):102-13. Available from: doi: 10.1097/HJR.0b013e328325d662.

26. Grace SL, Bennett S, Ardern Cl, Clark AM. Cardiac rehabilitation series: Canada. Prog Cardiovasc Dis [Internet]. 2014 [cited 2020 Dec 14];56(5):530-5. Available from: doi: 10.1016/j.pcad.2013.09.010.

27. Shanmugasegaram S, Oh P, Reid RD, McCumber T, Grace SL. Cardiac rehabilitation barriers by rurality and socioeconomic status: A cross-sectional study. Int J Equity Health [Internet]. 2013 [cited 2020 Dec 14];12(1). Available from: https://doi.org/10.1186/1475-9276-12-72.

28. Shanmugasegaram S, Oh P, Reid RD, McCumber T, Grace SL. A comparison of barriers to use of home- versus site-based cardiac rehabilitation. J Cardiopulm Rehabil Prev [Internet]. 2013 [cited 2020 Dec 14];33(5):297-302. Available from: doi: 10.1097/HCR.0b013e31829b6e81.

29 Brual J, Gravely S, Suskin N, Stewart DE, Grace SL. The role of clinical and geographic factors in the use of hospital versus homebased cardiac rehabilitation. International Journal of Rehabilitation Research [Internet]. 2012 [cited 2020 Dec 14];35(3):220-6. Available from: doi:10.1097/MRR.0b013e328353e375.

30. Piotrowicz E, Piotrowicz R. Cardiac telerehabilitation: current situation and future challenges. Eur J Prev Cardiol [Internet]. 2013 [cited 2020 Dec 14];20(S2):1-24. Available from: doi: 10.1177/2047487313487483c.

31. Leung YW, Brual J, Macpherson A, Grace SL. Geographic issues in cardiac rehabilitation utilization: A narrative review. Health and Place [Internet]. 2010 [cited 2020 Dec 14];16(6):1196-205. Available from: doi: 10.1016/j.healthplace.2010.08.004.

32. Tran M, Pesah E, Turk-Adawi K, Supervia M, Lopez Jimenez F, Oh P, et al. Cardiac Rehabilitation Availability and Delivery in Canada: How Does It Compare With Other High-Income Countries? Canadian Journal of Cardiology [Internet]. 2018 [cited $2021 \mathrm{Apr}$ 19];34:S252-S262. Available from: https://doi.org/10.1016/j.cjca.2018.07.413.

33. Besnier F, Gayda M, Nigam A, Juneau M, Bherer L. Cardiac Rehabilitation During Quarantine in COVID-19 Pandemic: Challenges for Center-Based Programs. Arch Phys Med Rehabil [Internet]. 2020 [cited 2020 Dec 14];101(10):1835-8. Available from: doi: 10.1016/j.apmr.2020.06.004.

34. Canada. Data Blog: Heart disease in Canada [Internet]. [Place unknown]: Government of Canada; 2018. [cited 2021 Feb 6]. Available from: https://health-infobase.canada.ca/datalab/heart- disease-blog.html. [Accessed 6th February 2021].

35. Grace SL, Turk-Adawi KI, Contractor A, Atrey A, Campbell NRC, Derman W, et al. Cardiac Rehabilitation Delivery Model for Low-Resource Settings: An International Council of Cardiovascular Prevention and Rehabilitation Consensus Statement. Progress in Cardiovascular Diseases [Internet]. 2016 [cited 2020 Dec 14];59(3):303-22. Available from: doi:10.1016/j.pcad.2016.08.004.

36. Higgins RO, Rogerson M, Murphy BM, Navaratnam H, Butler MV, Barker L, et al. Cardiac Rehabilitation Online Pilot: Extending Reach of Cardiac Rehabilitation. J Cardiovasc Nurs [Internet]. 2017 [cited 2020 Dec 14];32(1):7-13. Available from: doi:10.1097/JCN.0000000000000297.

37. Pfaeffli Dale L, Whittaker R, Dixon R, Stewart R, Jiang Y, Carter $\mathrm{K}$, et al. Acceptability of a mobile health exercise-based cardiac rehabilitation intervention: a randomized trial. J Cardiopulm Rehabil Prev [Internet]. 2015 [cited 2020 Dec 14];35(5):312-9. Available from: doi:10.1097/HCR.0000000000000125.

38. Rawstorn JC, Gant N, Rolleston A, Whittaker R, Stewart R, Benatar J, et al. End Users Want Alternative Intervention Delivery Models: Usability and Acceptability of the REMOTE-CR ExerciseBased Cardiac Telerehabilitation Program. Arch Phys Med Rehabil [Internet]. 2018 [cited 2020 Dec 14];99(11):2373-7. Available from: doi:10.1016/j.apmr.2018.06.027.

39. Mendell J, Bates J, Banner-Lukaris D, Horvat D, Kang B, Singer J, Ignaszewski A, Lear SA. What Do Patients Talk About? A Qualitative Analysis of Online Chat Sessions with Health Care Specialists During a "Virtual" Cardiac Rehabilitation Program. Telemedicine and e-Health [Internet]. 2019 [cited 2020 Dec 14];25(1):71-8. Available from: doi:10.1089/tmj.2017.0206.

40. Canadian Cardiovascular Society. Quality Indicators For Cardiac Rehabilitation and Secondary Prevention. [Internet]. Ottawa: The Canadian Cardiovascular Society; 2013. [cited 2021 Apr 19]. Available from: https://ccs.ca/app/uploads/2020/12/Indicator_CR.pdf.

41. Varnfield M, Karunanithi, MK, Särelä A, Garcia E, Fairfull A, Oldenburg BF, Walter DL. Uptake of a technology-assisted homecare cardiac rehabilitation program. MJA [Internet]. 2011 [cited 2020 Dec 14];194(4):S15-S9. Available from: doi: 10.5694/j.13265377.2011.tb02937.x

42. Banner D, Lear S, Kandola D, Singer J, Horvat D, Bates J, Ignaszewski A. The Experiences of Patients Undertaking a 'Virtual' Cardiac Rehabilitation Program. Glbal Telehealth [Internet]. 2015 [cited 2020 Dec 14]: 9-14. Available from: doi: 10.3233/978-161499-505-0-9.

43. Lear SA. The Delivery of Cardiac Rehabilitation Using Communications Technologies: The "Virtual" Cardiac Rehabilitation Program. Can J Cardiol [Internet]. 2018 [cited 2020 Dec 14];34(10 Suppl 2):S278-S83. Available from: doi: 10.1016/j.cjca.2018.07.009. 